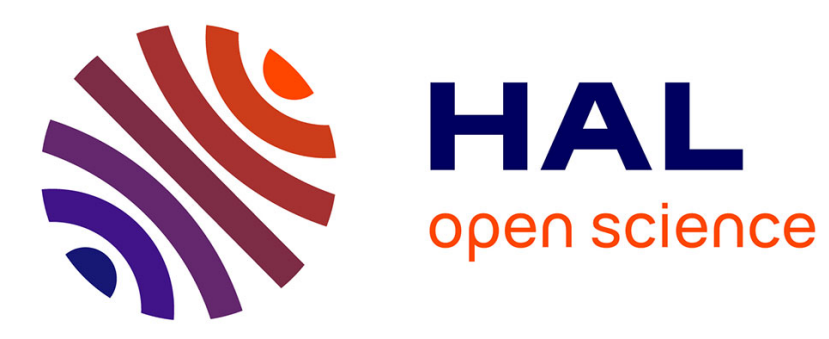

\title{
The Issues and Challenges in Copyright Protection for Agriculture Digital Publishing
}

\author{
Yuan-Yuan Tu
}

\section{To cite this version:}

Yuan-Yuan Tu. The Issues and Challenges in Copyright Protection for Agriculture Digital Publishing. 8th International Conference on Computer and Computing Technologies in Agriculture (CCTA), Sep 2014, Beijing, China. pp.419-425, 10.1007/978-3-319-19620-6_47 . hal-01420315

\section{HAL Id: hal-01420315 https://inria.hal.science/hal-01420315}

Submitted on 20 Dec 2016

HAL is a multi-disciplinary open access archive for the deposit and dissemination of scientific research documents, whether they are published or not. The documents may come from teaching and research institutions in France or abroad, or from public or private research centers.
L'archive ouverte pluridisciplinaire HAL, est destinée au dépôt et à la diffusion de documents scientifiques de niveau recherche, publiés ou non, émanant des établissements d'enseignement et de recherche français ou étrangers, des laboratoires publics ou privés. 


\title{
The issues and challenges in copyright protection for agriculture digital publishing
}

\author{
TU Yuan-yuan ${ }^{1 \mathrm{a}}$ \\ ${ }^{1}$ Agricultural Information Institute of Chinese Academy of Agricultural Sciences, Beijing, \\ 100081; ${ }^{2}$ Key Laboratory of Agricultural Information Service Technology (2006-2010), \\ Ministry of Agriculture, The People's Republic of China, Beijing, 100081 \\ a tuyuanyuan@caas.cn
}

\begin{abstract}
With the rapid development of agriculture information technology and Internet, the agriculture digital publishing has become one of the most dynamic industries in China. Currently, agriculture digital publishing just begun and the related laws and regulations are being improved. However, agriculture copyright protection for digital publishing still faces many problems and challenges. It is very important to strengthen agriculture copyright protection in digital publishing industry. In this paper, the main concepts and challenges for agriculture digital publishing and its copyright protection are analyzed and some suggestions are also proposed.
\end{abstract}

Keywords: Agriculture digital publishing; Agriculture copyright protection

\section{The concept of agriculture digital publishing and digital copyright protection}

\subsection{Agriculture digital publishing}

The rapid development of computer, Internet and communication technology, for the news publishing industry has brought significance and profound changes. The concept of agriculture digital publishing has become increasingly prominent, and was concerned by agriculture academic world. At present, there is no unified definition of agriculture digital publishing. It is generally believed that agriculture digital publishing is a new way of publishing by using digital technology and disseminating the digital content throughout the network. Its main features include agriculture digital content production, agriculture editing of digital processing, agriculture digital printing, agriculture digital management process, agriculture digital product form, agriculture digital distribution and sales, agriculture digital communication channels and agriculture digital reading consumption (Shi Yongqin, Zhang Fengjie, 2012).

The agriculture digital publications includes agriculture electronic books, agriculture digital newspapers, numeral agriculture magazines, agriculture network literature, agriculture network educational publications, agriculture network map, agriculture digital music, animation, agriculture network database publications, agriculture mobile phone publications (such as mobile phone MMS, customized ringing tone, mobile phone newspaper, mobile phone numeral magazines, mobile phone novels and 
mobile games) etc (see Table 1.). The speed of its development is amazing, and has begun to change the lifestyle and concept of consumption for the Chinese people, although the history of agriculture digital publishing in China is not for long.

Table 1. The character and life cycle of the agriculture digital publications

\begin{tabular}{|l|l|l|}
\hline \multicolumn{1}{|c|}{ Category } & \multicolumn{1}{c|}{ Character } & \multicolumn{1}{c|}{ Life cycle } \\
\hline Agriculture electronic books & Authentic, & More than two years \\
\hline Agriculture digital newspapers & Authentic & Update by days \\
\hline Numeral agriculture magazines & Comprehensive & Update by month \\
\hline Agriculture network literature & Fundamental & One year \\
\hline Agriculture network educational publications & Authentic & More than 3 years \\
\hline Agriculture network map & Universal, international & Real-time updates \\
\hline Agriculture digital music & Popular & More than two years \\
\hline Animation & New-emerging & One or two years \\
\hline Agriculture network database publications & New-emerging & Long-term \\
\hline Agriculture mobile phone publications & New-emerging & Update by days or month \\
\hline
\end{tabular}

\subsection{Agriculture digital copyright protection}

Agriculture digital copyright protection is managing and protecting the agriculture copyright of digital content in the whole life cycle of creation, production, dissemination, sales and uses through the various technical methods, in order to ensure the legal possession of digital content, the use of digital content, the dissemination of digital content and the management of digital content. It is commonly known as agriculture digital rights management (ADRM) or agriculture information rights management (AIRM). From the technical point of view, agriculture digital copyright protection is a kind of software technology related with rights management and rights restriction. From the application perspective, it is a complete system engineering which consists of agriculture digital copyright protection technology, agriculture business model and the agriculture laws and regulations (Shi Yongqin, Zhang Fengjie, Ma Chang, 2012).

Agriculture digital copyright protection is produced in the situation of agriculture digital content production, the contents of the personalized demand and marketing communication network. The difference is that the traditional agriculture copyright protection only protects the interests of the copyright owner, but agriculture digital copyright protection manages and protects the interests of value chain of digital production in the entire life cycle, which relates to the agriculture content production, agriculture processing management, agriculture transmission and sales, etc. It is an indispensable digital tool which assists agriculture copyright management. Speaking from this meaning, agriculture digital copyright protection is not a single copyright protection. It includes the agriculture digital rights to network, agriculture communication rights of information network, agriculture multimedia rights and other unknown rights of new pattern of network communication (Zhang Li, Chen Hanzhang, 2006). 


\section{The problems of agriculture digital publishing and copyright protection}

From now on, the first problem is that the base of agriculture digital publishing is still weak. The copyright protections are neglected. Strengthening the agriculture digital publishing has become the important thing.

In the meantime, technology provides space for agriculture digital publication, and enables consumer to become easy and simple on the copy of agriculture digital publishing works. Through the internet connection, the readers in the world are able to read agriculture digital publishing works quickly and easily, in order to meet their demands for fast reading. However, it increases the risk of agriculture digital publishing works piracy, and the legitimate rights of copyright owners get the great loss. In the era of agriculture digital publishing, the following main problems in agriculture digital copyright protection work are shown.

\subsection{The whole agriculture digital publishing recognize the existence of a misunderstanding}

Generally speaking, the attention of publishing enterprises is insufficient, and the understanding of their own position is not clear, with certain blindness on the implementation of agriculture digital publishing work. For example, a lot of presses proposed the transformation, it means that they only consider the transmission and operation, and neglect the mechanisms for web content.

Both the traditional publishing enterprises and the new digital publishing enterprises have experienced difficulty, because of the agriculture digital publishing chain is disjointed and fragmented, and imbalance for the distribution of interests caused by the management difficulties. On the other hand, the agriculture digital copyright regulation has no legal basis for compensation, not enough punishment and the high cost of rights system. It defects the pain and suffered from piracy problem.

In the traditional publishing system, the publishers as content processors have the duration of protection for intellectual property rights at the same time. In the field of agriculture digital publishing, the publishing business which use the term of copyright protection regulations effectively will hinder the agriculture digital information resources, thus publishing enterprises need to coordinate the relationship between the traditional paper-based and agriculture digital resources for the coordinated unification. It can not only maintain the present status of traditional paper-based agriculture resources, but also can do the agriculture digital resource content provider (Yan Xiaohong, 2013).

In addition, many publishing enterprises which are professional in agriculture field only stay in a digital publishing platform of construction. Although spent a lot of manpower and material resources on agriculture field, the follow-up work is still in 
the attempt and exploration. It is not clear on the way of agriculture digital environment content delivery. The result is that the agriculture content is in small scale, and the high quality publishing copyright is nothing. It likes building the house, if only put up the reinforcing steel bars, and no pouring concrete, it is still regarded as useless at all.

\subsection{Law of agriculture digital copyright protection is not perfect}

So far, it's no specialized in agriculture digital copyright protection laws in China. In the aspect of legislation, it lags behind the pace of digital publishing. Although some contents related with the promulgation of government regulations, most of them are for the technical measures, rather than the real content of work. It still can't be an agriculture system, and also can't solve all sorts of agriculture copyright disputes at present agriculture digital publishing era, even to mention the specialization and standardization of agriculture digital copyright protection.

For example, since March 1, 2013, the State Council revised "Regulations for the protection of computer software", "People's Republic of China Copyright Law Implementation Regulations" and "The right of communication through information network" has been officially implemented. For the three pieces of regulations, the administrative penalty fines were adjusted and modified. It only faces to all, and belongs to the technical measures. The adjustment and modification on the non technology level to the existing law is not even better. The new regulations on agriculture will be brought into being.

In a manner of speaking, the current law has appeared inadaptability gradually. It must be redesign the feasible mode of digital copyright protection. For example, a user sends a piece of original agriculture information on website, and then it will be copied or forwarded for tens of thousands of times in just a few minutes without notify. How to protect the copyright of original agriculture information? Is the "information" in the scope of agriculture copyright protection? This is a series of questions which bring the challenges to system and legal on agriculture digital copyright.

In addition, on the way of establishing digital copyright laws in China, it is very necessary to learn from the experience of western developed countries. USA made "Copyright law in 1976". It shows that the equipments or procedures in the field of entertainments and exhibitions contain the electronic delivery system and non-used or disclosed system, and provide the basis for the application of network copyright. After that, American digital publishing legal system has experienced the white paper "1995 intellectual property and the national information infrastructure", "1997 online copyright liability limit method", "Clear digital copyright and technology education law", "1998 digital millennium copyright law" (DMCA) and "2009 digital consumer's right to know act" and the development of other laws (Huang Xianrong, Li Weijuan, 2012). 
USA is the one of most important countries which received attention to copyright legislation and enforcement in the world. In the continuous improvement of IPR legislation and enforcement of protection at the same time, protecting the legal interests of copyright owners effectively, and maintain the order of the copyright under the digital environment. It provides a model for establishing the legal system of digital copyright protection in China. It will effect on the development of agriculture digital copyright laws in the future.

\subsection{Agriculture digital copyright resources are scattered and unable to form an effective system of agriculture digital copyright protection}

The scattered agriculture digital copyright resources refers that there is no clear boundaries among the publishing enterprises, the copyright owner and the third parties. Some for their respective camps, some two-two union, failed to form a set of effective specification of the agriculture digital publishing industry chain, and leading to the problem of agriculture copyright protection is more complicated and changeable.

If we suppose that a spurt of progress of technology of agriculture digital publishing third enterprises are growing, and the agriculture digital publishing activities is developing rapidly, the author of publishing enterprises or digital copyright will not get reasonable returns in the business, eventually they will be reluctant to digital copyright to cooperate with the third party of digital publishing enterprises. This is just one of these situations.

As it is not yet mature in the digital publishing business model, to digital publishing enterprises, the third party publishing enterprises and the author or copyright owners alike, no one can tell you how much really get from the agriculture digital publishing ( Xu Xinghua, 2013).

A series of potential crisis also revealed, it confused the original intention of agriculture digital publishing. How to develop the agriculture copyright protection in the digital publishing industry? How to break through the bottleneck of agriculture digital copyright in order to form a healthy value chain? How to keep the maximize benefits on most aspects of the industry chain? These problems all need to be solved urgently.

\subsection{Cloud computing brings new opportunities for agriculture copyright protection, also brings new problems}

Cloud computing is a calculation based on internet (as shown in Fig. 1.). 


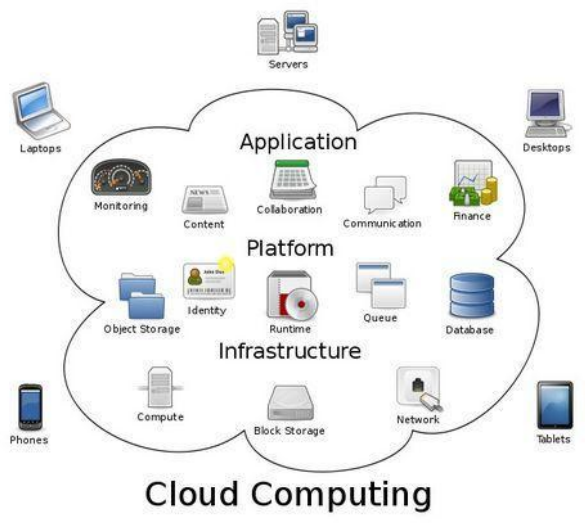

Fig. 1. What is cloud computing

In this way, the hardware and software resources and information can be provided to computers and other devices on demand. The technology applies after the agriculture digital publishing, its dissemination of information on the breadth and depth is unprecedented. It will be published in the traditional publishing enterprises, authors and the third-party of digital publishing enterprises was jointed on a chain. According to their interests, they plays different roles (as shown in Fig. 2.).

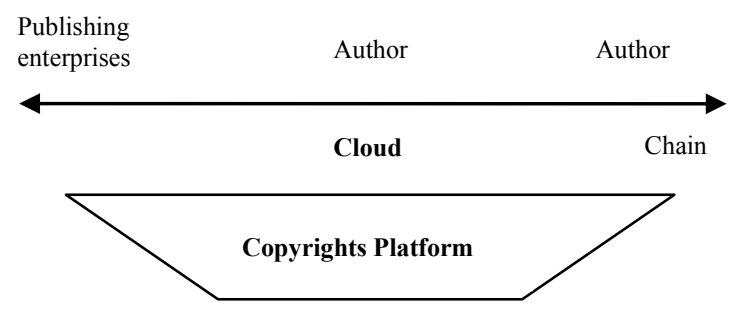

Fig. 2. The dissemination of roles

Meanwhile, the environment of agriculture digital publishing will be changed. The advantage of the improvement is that the distributing agriculture digital publishing resources on a unified and open platform for publishing services will be integrated on cloud platform. For example, the publishing companies can publish on the cloud platform by choosing different distribution channels which carried on the agriculture digital publishing technology to encrypt and regulate. A variety of channels can be integrated in the third-party of agriculture digital publishing for the terminal applications on the cloud platform. When enjoying the advantages of cloud computing, it has led to changes in transaction costs as a new technology, inevitably adds to challenge in the future (Zhou Liang, 2012). For example, the piracy illegal uses of agriculture works flood in market throughout a common cloud without the permission of the copyright holder. Now many third parties companies provide cloud storage service, but they have to review the data before storing. That is to ensure the data is safe and unauthorized users can't access these data. If the shared object is 
certain groups, it is so much for the impact of the copyright holder, but if it is for the individual, it is damaging the interests of the copyright owner. Even if the copyright holder requests cloud storage service providers to cancel the sharing links. They still can't control the piracy activities.

\section{The countermeasures and suggestions on strengthening copyright protection of agriculture digital publishing}

First, the legislative branch should actively promote the establishment of a special digital copyright protection laws, and the new regulations on agriculture will be brought into being. For the publishing companies, copyright holders and third-party digital publishing business, there are laws to go by. It ensures the sound development of agriculture digital publishing chain and the accomplishment of their interests.

Second, from a relatively weak awareness to a transformation process, the acceleration of the agriculture digital publishing business of copyright protection can avoid vicious competition among enterprises, thus driving to respond positively to the agriculture digital copyright protection, and ultimately form a good environment for agriculture digital rights protection.

Finally, the advanced digital technology (e.g. cloud computing) is a hardware protection of agriculture digital copyright protection. It can support digital copyright protection system, and promote the coordinated development of digital copyright protection laws and regulations in agriculture.

In the era of agriculture digital publishing, the developing of agriculture copyright protection is certainly full of hard troubles. The agriculture digital copyright protection is bound to meet new round of challenges in the spiraling process of continuous innovation and improvement.

\section{ACKNOWLEDGEMENTS}

The work is supported by the Academy of Science and Technology for Developm ent fund project "The research about the content organizing and service pattern for website resources of Chinese Academy of Agricultural Sciences", and the special fund project for Basic Science Research Business Fee, AII (No. 2014-J-008). 


\section{References}

1. Shi Yongqin, Zhang Fengjie (2012). Beijing. Digital Rights Concept Analysis. China Publishing, 61-64.

2. Shi Yongqin, Zhang Fengjie, Ma Chang (2012). Beijing. The concept of digital copyright protection technology, types and its application in the field of publishing [J], 57-59.

3. Zhang Li, Chen Hanzhang (2006).Beijing. The concept of digital publishing. http://tech.sina.com.cn/other/2006-09-29/16201166788.shtml.

4. Yan Xiaohong (2013). Beijing. Several problems about digital publishing and copyright. The academic lectures in publishing research center of Communication University of China.

5. Huang Xianrong, Li Weijuan (2012). Beijing. The American legal system present situation and development trend of digital publishing [J].Chinese Publishing,59-62.

6. Xu Xinghua (2013). Bao Ding. Digital copyright protection under the digital publishing perspective: the status quo, problems and countermeasures. Baoding college journal, 116119.

7. Zhou Liang (2012). Suzhou. Cloud computing technology digital copyright protection[M]. The master's degree thesis of Suzhou University .

8. Li Xiaolin (2010). Beijing. The analysis of copyright in digital publishing industry . Electronic intellectual property, 69-73. 